\title{
Modelling Time to Mortality with Congestive Heart Failure: A Case Study in Wollo General and Referral Government Hospitals
}

\author{
Habtamu Dessie $^{1}$, Yenefenta Wube ${ }^{1}$, Belete Adelo ${ }^{1}$, Eskeziaw Abebe ${ }^{2}$ \\ ${ }^{1}$ Department of Statistics, Faculty of Natural and Computational Science, Woldia University, Woldia, Ethiopia \\ ${ }^{2}$ Department of Midwifery, Faculty of Natural and Computational Science, Woldia University, Woldia, Ethiopia
}

Email address:

Habtamudessie54@gmail.com (H. Dessie),yenewub09@gmail.com(Y.Wube)

\section{To cite this article:}

Habtamu Dessie, Yenefenta Wube, Belete Adelo, Eskeziaw Abebe. Modelling Time to Mortality with Congestive Heart Failure: A Case Study in Wollo General and Referral Government Hospitals. American Journal of Theoretical and Applied Statistics.

Vol. 9, No. 2, 2020, pp. 21-36. doi: 10.11648/j.ajtas.20200903.11

Received: October 7, 2019; Accepted: April 16, 2020; Published: April 28, 2020

\begin{abstract}
Congestive heart failure is a complex clinical syndrome of functional or structural impairment in the heart. Nowadays heart failure is common and increasing in the world and researches on this area is limited. Therefore the aim of the present study was to analyze and quantify the impact of modelling heart failure survival allowing for covariates with time varying effects known to be independent predictors of overall mortality in this clinical setting. A retrospective cohort study was conducted on CHF patients who were on treatment follow up at both WGH and DRH from January 1, 2010 to December 30, 2016. A total of 487 patients were selected by using simple random sampling from the patient's medical record. Semi parametric, parametric PH models and AFT models was employed to identify the best model which shown as the real causation of factors with the outcome of CHF which is death. The Weibull accelerated failure time model result showed that the risk factors related to accelerating or decelerating the lifespan were age $(\mathrm{TR}=0.962, \mathrm{p}=0.000)$, Residence (rural) $(\mathrm{TR}=1.24$, $\mathrm{p}=0.019)$, Nutritional (Poor) ( $\mathrm{TR}=0.582, \mathrm{p}=0.000)$, Smoking ( $\mathrm{TR}=0.774, \mathrm{p}=0.005)$, Alcoholism $(\mathrm{TR}=1.394, \mathrm{p}=0.010$ ), Diabetes mellitus $(T R=0.49, p=0.000)$, Hypertension $(T R=0.079, p=0.019)$, Stroke $(T R=0.799, p=0.014)$, Coronary Artery disease $(\mathrm{TR}=0.276, \mathrm{p}=0.012)$, Tuberculosis bacillus $(\mathrm{TR}=0.103, \mathrm{p}=0.000)$ as a co morbidity and the interaction between age and Tuberculosis bacillus $(\mathrm{p}=0.000)$, age and Coronary artery disease $(\mathrm{p}=0.041)$, Diabetes mellitus with Hypertension $(p=0.000)$, Hypertension with Nutritional status $(p=0.000)$ and age with time $(p=0.000)$ were found statistically significant. The Weibull accelerated failure time model performed better explain the effect of predictors than other Cox and parametric $\mathrm{PH}$ models. Thus, researchers should use parametric AFT models to see regression varying effect covariates. Frequent monitoring and follow up of Patients with heart failure should be adopted.
\end{abstract}

Keywords: CHF, Retrospective Cohort Study, Parametric AFT Model, Censoring, Mortality

\section{Background}

Heart failure is often used to mean chronic heart failure or congestive heart failure (CHF). Clinically it is impossible to define Heart Failure by a single term as a result it is defined as a complex clinical syndrome in which there is a functional or structural impairment in the heart. This can result from any functional or structural cardiac disorder and it impairs the ventricle's ability to fill with or eject blood and to deliver oxygenated blood corresponding to the requirements of the metabolizing tissues of the body and/or doing so at increased filling pressures [1]. Heart failure (HF) is progressive and irreversible which occurs more slowly because of damage to the heart muscle, building up through time due to disease of the heart or a blood vessel leading from the heart as a result of various diseases, accordingly it is a serious clinical condition which represents the end-stage of numerous other cardiac diseases [2].

Heart failure is a major clinical problem worldwide, reaching an epidemic level in the developed world with no known cure at this time. Approximately 26 million people worldwide are living with heart failure, and nearly 1 million 
new cases are diagnosed annually worldwide, making it the most rapidly growing cardiovascular disorder. In economically developed countries, up to one person in five is expected to develop heart failure at some point in their life and it affects $1-3 \%$ of the general population [2]. It is predominantly seen in the geriatric population in these countries, with almost $80 \%$ of cases occurring in patients over the age of 65 . Thus, prevalence of heart failure has been shown to follow an exponential pattern, which rises with age and affects $6-10 \%$ of people over age 65 [3].

Despite improvements in care over the past 20 years, the outlook for patients with heart failure remains poor, and it has a higher mortality than many of the common malignancies [1, 2]. One year mortality in developed countries is approximately $20 \%$ while the 5 -year mortality is approximately $50-65 \%$ in population-based studies [1]. In a study conducted in Ghana the high prevalence of heart failure of $76 \%$ seen in the study supports the fact that HF is a major contributor to cardiovascular disease burden in sub-Saharan Africa [3]. Similar findings have been reported from Cameroon where heart failure is found to be the fifth to sixth cause of hospital admissions [4]. In other parts of subSaharan Africa, heart failure has been found to account to 5\% to $10 \%$ of hospital admissions [3]. Compared to studies from other parts of the world, heart failure in Africa tends to occur at a much younger age with most cases recorded around the 5 th and 6th decade and it is not a disease of the elderly in sub-Saharan Africa [2]. This young age reflect the major contribution of rheumatic valvular disease to heart failure, but could also be accounted for infections as it remain a common cause of heart failure in many parts of the world including Africa and can strike at any age. Hospital case fatality among those with heart failure in Africa ranges from $9 \%$ to $12.5 \%$. This consistent death rate ranks heart failure among the major causes of death of cardiovascular origin in Africa [5].

In Ethiopia the prevalence and mortality associated with major non-communicable diseases in Ethiopia found cardiovascular disease accounted for 3\%-12.6\% hospital admission and found to have increased between 1970s and 2000s. And also they found congestive heart failure reported to have caused $2.5 \%$ of deaths among all age-groups in a sampled hospital-based mortality study [6]. Similarly a study conducted by analyzing surveillance data on causes of death in Addis Ababa found that, the leading cause of death was cardiovascular disease causing $24 \%$ of all death. Congestive heart failure is found to be the third cause of death following hypertension and stroke among the cardiovascular disease deaths [7]. Similar study conducted on Survival during Treatment Period of Patients with Severe Heart Failure Admitted to Intensive Care Unit (ICU) at Gondar University Hospital found that congestive heart failure reported to have caused $12.5 \%$ of deaths among all age groups [8]. Nowadays cardiovascular disease has become one of the major causes of premature death and disability in low and middle income countries. However, heart failure as cardiovascular complication remains unexplored largely in Africa [9]. The long-term prognosis associated with HF is also poor [10].

Thus, the limited work on the area and lack of appropriateness of the model applied for data have generated interest in assessing factors affecting timing of death by fitting a statistical model that can explain the data in most meaningful manner. However AFT models are relatively unfamiliar and seen rarely in medical research papers [11]. Primary Several models have been designed to predict survival of patients with heart failure. These, while available and widely used for both stratifying and deciding upon different treatment options on the individual level, have several limitations. Specifically, some clinical variables that may influence prognosis may have an influence that change over time. Statistical models that include such characteristic may help in evaluating prognosis. The aim of the present study is to analyze and quantify the impact of modelling heart failure survival allowing for covariates with time-varying effects known to be independent predictors of overall mortality in this clinical setting. Therefore, in this study the main objective was to compare cox proportional hazard and accelerated failure time models using heart failure dataset and explores the time-varying effect of the different covariates known to be predictive of mortality in such clinical scenario and highlight the importance of considering such details in the modelling of heart failure mortality.

\section{Methods and Materials}

\subsection{Study Area and Settings}

This study was conducted in both Woldia general and Dessie referral hospitals. Wollo found Northeast of Ethiopia, found in Amhara regional state of Ethiopia. Specifically, the data for this study was obtained from out ward patients in the internal medicine department in those hospitals.

\subsection{Study Design and Period}

Secondary data was taken from the patients follow up chart from January 1, 2010 to December 30, 2016. Retrospective cohort study was employed.

\subsection{Source and Study Population}

The source of population in this study was all CHF patients attend at Wollo general and referral hospitals during the study period January 1, 2010 to December 30, 2016. And the study population was All CHF patients were included as part of a secondary cohort of HF individuals who attend at a cardiology general and referral Wollo hospitals, Ethiopia. The ascertainment period was from January 1, 2010 to Dec. 30, 2016. The classification of the etiologies of heart failure was follow from the different literatures. As such, the diagnosis of chronic heart failure would make through both clinical and imaging procedures when necessary. Beginning of follow-up was defined as enrolment in the protocol. Last follow-up was evaluated in Dec. 30, 2016. 


\subsection{Inclusion and Exclusion Criteria}

All CHF patients who follow up in hospital during the study period were included. All CHF patients who follow up in hospital during the study period and had other diseases as co morbidity was included. On the other hand all patients without $\mathrm{CHF}$ case are not included in the study. Also CHF patients died with other case were not considering as our failure event in the study. Finally, a patient's first seen department is not CHF case was not included in this study.

\subsection{Sample Size and Sampling Procedures}

Sample size is calculated based on the single population proportion formula to the size by considering the following points. Proportion of death in CHF is $12.5 \%$ [8]. $(\alpha=5 \%)$ level of significance and 3\% margin of error (d).

$$
n=\frac{z_{\frac{\alpha}{2}}^{2} p(1-p)}{d^{2}}
$$

where critical value at $95 \% \mathrm{CI}$ of certainty 1.96

$$
\mathrm{n}=(1.96)^{2} * 0.125(1-0.125)=486.66(0.03)^{2}
$$

The total CHF patients attending at hospital between January 1, 2010 to Dec. 30, 2016300 sample patients out of 6037 cases from DRH and 187 out of 3763 from WGH. The samples was allocated using probability proportion to size and a total of $487 \mathrm{CHF}$ patients from the two sites was selected using simple random sampling method.

\subsection{Variables in the Study}

\subsubsection{Dependent Variable}

Survival analysis always measures the time from a defined starting point to the occurrence of a given event. In this study the response variable measures the length of treatment time from inward entry to event or censoring and the event of interest is death.

\subsubsection{Independent Variables}

The most important expected correlates of the survival experience of patients with $\mathrm{CHF}$ from literature reviews and their theoretical justification were included in this study. And they are grouped as clinical and demographic variables, and comorbidity conditions. Categorical predictors and Continuous predictors are systolic blood pressure, weight, heart rate, white blood cell count (WBCC) and duration of heart failure are included in this study.

\subsection{Data Collection Tools and Techniques and Data Processing}

The data was collected from heart failure patients follow up chart in Wollo general and referral hospitals by twelve trained nurses in profession as data collectors and with three supervisors. Three supervisor and six data collectors were selected from each hospital residing in Wollo zone and they were trained how they supervise and collect data accordingly for 3 days. Also they were practice how they review documents before the data collection. The supervisors and investigators were closely follow the data collection process and ensure completeness and consistency of the collected information daily until data collection ends. After the data collection, data editing, data entry and cleaning process of questionnaire was done and entered into SPSS version 20 and exported to STATA V. 12 for data analysis. Analysis of frequency of different variables was done using both STATA and SPSS.

\subsection{Ethical Consideration}

Prior to data collection ethical approval for the study was obtained from Institutionalized Review Board, Faculty of Natural and computational Science research and community service, Woldia University. And also the objectives of the study were explained to the medical directors to get permission. In addition, the participants identifier was not recorded anywhere for the sake of confidentiality.

\subsection{Method of Data Analysis}

\subsubsection{Survival Analysis}

The survival and hazard functions are key concepts in survival analysis for describing the distribution of survival times. The survivor function $s(t)$ is the probability that the survival time of a randomly selected subject is greater than some specified time, $t$ or the probability of an individual being event-free beyond time, $t$ [12]. In order to find the survival function, suppose $\mathrm{T}$ be random variable associated with the survival times, $t$ be the observed value of the random variable $\mathrm{T}$ and $f(t)$ be the underlying probability density function of the survival time $t$. The cumulative distribution function, $F(t)$ represents the probability that an individual selected at random will have a survival time less than or equal to the specified value, $t$. Thus, the cumulative distribution function and the survivor function are given by:

$$
\begin{gathered}
F(t)=p(T \leq t)=\int_{0}^{t} f(u) d u, t \geq 0 \\
s(t)=p(T>t)=1-F(t), t \geq 0
\end{gathered}
$$

The relationship between $(t)$ and $f(t)$ is given as

$$
\mathrm{f}(t)=\frac{d}{d t} F(t)=\frac{d}{d t}(1-s(t))=-\frac{d}{d t} s(t), t \geq 0
$$

Hazard function $h(t)$ :

The hazard function is generally denoted by $h(t)$ and can be used to express the risk or hazard of death at time, $t$. It will be obtained from the probability that an individual dies in an infinite, simply small interval $(t, \Delta t)$ given that the individual has survived up to time, $t$. i.e.

$$
\left\{t \leq T<\frac{\nabla t}{T} \geq t\right\}
$$

There is a clearly defined relationship between $(t)$ and $h(t)$ which is given by the formula

$$
h(t)=\frac{f(t)}{1-F(t)}=\frac{f(t)}{s(t)}=\frac{-d}{d t} \ln S(t)
$$




$$
S(t)=\exp \left[-\int_{0}^{\mathrm{t}} \mathrm{h}(\mathrm{u}) \mathrm{du}\right]=\exp (-\mathrm{H}(\mathrm{t}), \mathrm{t} \geq 0
$$

Where $H(t)=\int_{0}^{t} h(u) d u$ the cumulative hazard function, which can be obtained from

$$
H(t)=-\log (S(t))
$$

The probability density function of $T$ can be written as $f(t)=h(t) S(t)$. The study was focus on time to event (time to death by CHF), so the appropriate method for this particular study is survival analysis. Kaplan-Meir estimator and Cox proportional hazard model and AFT model was used for summarizing and analysis and model building respectively. Also, we used log rank tests to study survival pattern and Wilcox on tests for comparison of survival functions.

\subsubsection{Cox Proportional Hazards Model.}

Cox proposed a semi parametric model for the hazard function that allows the addition of explanatory variables, but keeps the baseline hazard as an arbitrary, unspecified, nonnegative function of time. The Cox model specifies the hazard function as [13]

$$
h(t ; x)=h o(t) \exp \left(\beta^{\prime} x\right)
$$

Where $x$ is a vector of covariates and $\beta$ is the corresponding regression parameter and the baseline hazard $h_{0}(t)$ in (4) corresponding, $t$ the hazard function when all covariates equal zero.

One of the restrictions underlying the Cox model with timefixed covariates is its proportional hazards $(\mathrm{PH})$ assumption. It follows from (3.4) that the hazard ratio between two sets of covariates is constant over time, because the common baseline hazard function cancels out in the ratio of the two hazards. For fixed-time covariates, the exponent of a coefficient describes the relative risk due to the covariate $h(t ; x)$

$$
\frac{h(t ; x)}{h o(t)}=\exp \left(\beta^{\prime} x\right)
$$

\subsubsection{Accelerated Failure Time Model}

AFT models work to measure the effect of covariate to "accelerate" or to "decelerate" survival time meaning the effect of covariate is multiplicative on time scale $\left(\exp \left(\beta^{\prime} x\right)\right)$ It is indicating how a change in covariate values changes the time scale from the baseline time scale. Under AFT models the survival function of the $i^{t h}$ individual with covariates $x_{1}, x_{2}, \ldots, x_{p}$ at time, $t$ is the same as the survival function of an individual with a baseline survival function at a time, $t$. mathematically, it can be expressed with its corresponding hazard function as:

$$
\begin{gathered}
S_{i}(t ; x)=S_{0}\left[\exp \left(\beta^{\prime} x\right) t\right] \\
h i(t ; x)=\exp \left(\beta^{\prime} x\right) h_{0}\left(\exp \left(\beta^{\prime} x\right) t\right)
\end{gathered}
$$

Where $\hat{\beta}^{\prime}=\left(\hat{\beta}_{1}, \hat{\beta}_{2,}, \widehat{\beta}_{3, \ldots}, \widehat{\beta}_{p}\right)$ is a vector of regression coefficients $S_{0}(t)$ and $h_{0}(t)$ are the baseline survival and hazard functions respectively. The effect size for the AFT model is measured using the time ratio (TR) which is a ratio of the survival time of an individual with an exposure to the survival time of an individual without the exposure for a given survival probability.

Suppose, $T_{i}$ is a random variable representing the survival time for the $t_{i}$ individual. Then representation of the relationship between covariate values and survival time in the AFT model is the linear relationship between log time and the covariate values expressed as follows:

$$
\log T i=\mu+\beta^{\prime} X_{i}+\delta \varepsilon_{i}
$$

Where $\hat{\beta}^{\prime}=\left(\hat{\beta}_{1}, \hat{\beta}_{2,}, \hat{\beta}_{3,}, \hat{\beta}_{p}\right), \mu$ is intercept,$\delta$ is scale parameter and $\varepsilon_{i}$ is a random variable used to model the deviation of values of $\log T i$ from the linear part of the model. $\varepsilon_{i}$ is random error distribution assumed to have a particular probability distribution supposed to be followed by the survival time under study.

Under the AFT formulation, the effect of treatments and covariates is assumed to act additively on the log time scale and therefore multiplicatively on the time scale itself. Three commonly adopted parametric AFT models are the Weibull, log-normal, and log-logistic in terms of the distribution of survival time. AFT models are fitted using the maximum likelihood estimation method. The likelihood function of $n$ observed survival times, $\left(t_{1}, t_{2}, t_{3}, \ldots,, t_{p}\right)$ for the log-linear form of the AFT model is given by:

$$
L(\beta, \mu, \sigma)=\prod_{i=1}^{n}\left[f_{i}\left(t_{i}\right)^{\delta i}\left[S_{i}\left(t_{i}\right)\right]^{(1-\delta i)}\right.
$$

Where $f_{i}\left(t_{i}\right)$ and $S_{i}\left(t_{i}\right)$ are the density and survival functions for the, $i^{t h}$ individual at time $t_{i}$ and $\delta_{i}$ is the event indicator for the observation and has value zero for censored and one for uncensored individuals. If $f_{z i}(z i)$ and $f_{z i}(z i)$ are probability density function and survival function respectively of the random variable $\varepsilon_{i}$ in such a way that

$$
\begin{aligned}
s_{i}(\mathrm{t}) & =S_{z i}(z i) . \\
f_{i}\left(t_{i}\right) & =\frac{1}{\sigma t_{i}} f_{z i}(z i)
\end{aligned}
$$

And, where

$$
z_{i}=\left(\log _{i}-\left(\mu+\beta_{1} x_{1 i}+\beta_{2} x_{2 i}+\beta_{3} x_{3 i}+\cdots+\beta_{p} x_{p i}\right)\right)
$$

\section{Result and Discussion}

\subsection{Descriptive Statistics}

The medical cards of 487 patients have been reviewed of which $42.1 \%$ (total 205) are death cases. A death proportion seems lower for females $(38.19 \%)$ than for males $(47.74 \%)$. The Divorced group showed the highest percentage $(62.86 \%)$ with respect to death proportions than the other three groups and HIV positive groups revealed the highest proportion of death $(76.19 \%)$. A death proportion seems lower for rural residences $(40.76 \%)$ than for Urban $(43.19 \%)$ patients. While on the other hand the death proportion of patients who have had poor nutrition status (51.48\%) seems higher than those of 
who have good nutrition habit (26.37\%). CHF patients with than have no TB co infection. In the same fashion we TB co infection have the highest death proportion $(89.9 \%)$ describe the rest variables under table 1 below:

Table 1. Demographic and Health factors by CHF death at medical wards of Woldia general and Dessie referral hospitals, Ethiopia, $2017 / 2018$.

\begin{tabular}{|c|c|c|c|c|c|c|c|}
\hline \multirow{2}{*}{$\begin{array}{l}\text { Demographic and } \\
\text { Health factors }\end{array}$} & \multirow{2}{*}{ Stratum } & \multirow{2}{*}{ Value } & \multirow{2}{*}{ Total } & \multirow{2}{*}{ Median survival time (in months) } & \multicolumn{3}{|l|}{ Status } \\
\hline & & & & & Event/Death & Censored & Percent Death \\
\hline \multirow{2}{*}{ Sex } & 1 & (0) Male & 199 & 15.19 & 95 & 104 & 47.74 \\
\hline & 2 & (1) Female & 288 & 36.1 & 110 & 178 & 38.19 \\
\hline \multirow{2}{*}{ Residence } & 1 & (0) Urban & 276 & 35 & 119 & 157 & 43.11 \\
\hline & 2 & (1) Rural & 211 & 16 & 86 & 125 & 40.76 \\
\hline \multirow{3}{*}{ Nutritional } & 1 & (0) Poor & 305 & 14.1 & 157 & 148 & 51.48 \\
\hline & 2 & (1) Good & 182 & 42 & 48 & 134 & 26.37 \\
\hline & 1 & (0) Under & 202 & 26 & 97 & 105 & 48.02 \\
\hline \multirow[t]{3}{*}{ Weight } & 2 & (1) Normal & 231 & 36.2 & 72 & 159 & 31.17 \\
\hline & 3 & (2) Over & 54 & 17.4 & 36 & 18 & 66.67 \\
\hline & 1 & (0) Single & 115 & 36.24 & 31 & 84 & 26.96 \\
\hline \multirow{3}{*}{ Marital Status } & 2 & (1) Married & 294 & 26 & 128 & 166 & 43.54 \\
\hline & 3 & (2) Divorced & 35 & 16 & 22 & 13 & 62.86 \\
\hline & 4 & (3) Widowed & 43 & 37 & 24 & 19 & 55.81 \\
\hline \multirow{2}{*}{ Smoking Status } & 1 & (0) No & 430 & 29.95 & 153 & 277 & 35.58 \\
\hline & 2 & (1) Yes & 57 & 23.93 & 52 & 5 & 91.23 \\
\hline \multirow{2}{*}{ Religion } & 1 & (0) Orthodox & 237 & 30.09 & 84 & 153 & 35.44 \\
\hline & 2 & (1) Muslim & 250 & 25.23 & 121 & 129 & 48.4 \\
\hline \multirow{2}{*}{ Educational status } & 1 & (0) Illiterate & 168 & 31 & 70 & 98 & 41.67 \\
\hline & 2 & (1) Literate & 139 & 25 & 135 & 184 & 97.12 \\
\hline \multirow{2}{*}{ Alcoholism } & 1 & (0) No & 444 & 35 & 177 & 267 & 39.86 \\
\hline & 2 & (1) Yes & 43 & 14 & 28 & 15 & 65.12 \\
\hline \multirow{2}{*}{ Diabetes Miletus } & 1 & (0) No & 436 & 26 & 167 & 269 & 38.30 \\
\hline & 2 & (1) Yes & 51 & 25 & 38 & 13 & 74.51 \\
\hline \multirow{2}{*}{ CKD } & 1 & (0) No & 439 & 35 & 168 & 271 & 38.27 \\
\hline & 2 & (1) Yes & 48 & 17.4 & 37 & 11 & 77.08 \\
\hline \multirow{2}{*}{ Presence of pneumonia } & 1 & (0) No & 455 & 35 & 178 & 178 & 39.12 \\
\hline & 2 & (1) Yes & 32 & 13 & 27 & 27 & 84.38 \\
\hline \multirow{2}{*}{ CAD } & 1 & (0) No & 467 & 35 & 188 & 279 & 40.26 \\
\hline & 2 & (1) Yes & 20 & 13 & 17 & 3 & 85.0 \\
\hline \multirow{2}{*}{ HTN } & 1 & (0) No & 327 & 36.1 & 100 & 227 & 30.58 \\
\hline & 2 & (1) Yes & 160 & 14 & 105 & 55 & 65.62 \\
\hline \multirow{2}{*}{ Stroke } & 1 & (0) No & 429 & 36.1 & 152 & 277 & 35.43 \\
\hline & 2 & (1) Yes & 58 & 13 & 53 & 5 & 91.38 \\
\hline \multirow{2}{*}{ TB } & 1 & (0) No & 388 & 36.2 & 116 & 272 & 29.90 \\
\hline & 2 & (1) Yes & 99 & 13 & 89 & 10 & 89.90 \\
\hline \multirow{2}{*}{ HIV } & 1 & (0) No & 403 & 35 & 147 & 262 & 36.48 \\
\hline & 2 & (1) Yes & 84 & 17.4 & 64 & 20 & 76.19 \\
\hline
\end{tabular}

The mean baseline age of the participants was 50 years. Ranging from 16 to 86 and standard deviation of 19 years. The mean systolic blood pressure of the participants was 116 . Ranging from 80 and 180 and standard deviation of 20. Similarly for Heart rate of the patients in Table 2.

Table 2. Continuous variable characteristics of the study participants.

\begin{tabular}{|c|c|c|c|c|c|}
\hline Variable & $\mathbf{N}$ & Minimum & Maximum & Mean & Std. Deviation \\
\hline Baseline age of patients & 487 & 16 & 86 & 49.81 & 18.984 \\
\hline Systolic blood pressure & 487 & 80 & 180 & 116.12 & 19.490 \\
\hline Heart rate of the patients & 487 & 23 & 120 & 82.57 & 13.957 \\
\hline
\end{tabular}

\subsection{Cox Proportional Hazards Model}

The non parametric method does not control for covariates and it requires categorical predictors. Therefore here we used Cox PH for dealing the covariate effects along with the survival time. The Cox model identified significant predictors at $25 \%$ level. Consequently, the candidate variables for building a multivariable Cox model are place of residence, Sex, Age, Nutritional Status, Smoking Status, Religion, Alcoholism, Baseline Weight as (under, Normal \&
Over weight), Heart Rate, Systolic Blood Pressure, Presence of Diabetes Mellitus, Presence Of Hypertension, Presence of Coronary Kidney Disease, Presence of HIV, Presence of Pneumonia, Presence of Tuberculosis, Presence of Stroke And Presence of Coronary Artery Disease as co morbidity. Whereas Marital Status and Educational Status of the patients are not a candidate variable for main effect models at $25 \%$ level of significance. Hence the two covariates are not important for the building of the main effect only multivariable models. Univariable Cox proportional hazard 
model STATA V. 12 summary results of the hazards ratio, $75 \%$ are presented in table 3 .

confidence intervals and standard errors for each covariate

Table 3. Univariable analysis of Cox proportional hazard model result WGH\&DRH, 2017.

\begin{tabular}{|c|c|c|c|c|c|}
\hline \multirow{2}{*}{ Factors } & \multirow{2}{*}{ HR } & \multirow{2}{*}{ S.E } & \multirow{2}{*}{ P_value } & \multicolumn{2}{|l|}{$75 \% \mathrm{CI}$} \\
\hline & & & & Lower & Upper \\
\hline \multicolumn{6}{|c|}{ Sex (Ref.=Male) } \\
\hline Female & 0.62 & 0.09 & 0.001 & 0.53 & 0.73 \\
\hline Age & 1.03 & 0.004 & 0.000 & 1.02 & 1.03 \\
\hline \multicolumn{6}{|c|}{ Residence (Ref.=Urban) } \\
\hline Rural & 1.44 & 0.21 & 0.011 & 1.22 & 1.70 \\
\hline \multicolumn{6}{|c|}{ Marital Status (Ref.=Windowed)* } \\
\hline Single & 0.75 & 0.21 & 0.309 & 0.55 & 1.04 \\
\hline Married & 0.80 & 0.18 & 0.311 & 0.61 & 1.03 \\
\hline Divorced & 0.93 & 0.28 & 0.813 & 0.66 & 1.32 \\
\hline \multicolumn{6}{|c|}{ Nutritional Status (Ref.=Poor) } \\
\hline Good & 0.36 & 0.06 & 0.000 & 0.30 & 0.44 \\
\hline \multicolumn{6}{|c|}{ Smoking (Ref.=No) } \\
\hline Yes & 1.59 & 0.26 & 0.005 & 1.31 & 1.92 \\
\hline \multicolumn{6}{|c|}{ Religion $($ Ref. $=$ others $)$} \\
\hline Orthodox & 1.52 & 0.22 & 0.004 & 1.29 & 1.79 \\
\hline Muslim & Omitted & & & & \\
\hline \multicolumn{6}{|c|}{ Educational Status (Ref.=illiterate)* } \\
\hline Literate & 1.11 & .16 & 0.465 & 0.94 & 1.32 \\
\hline \multicolumn{6}{|c|}{ Alcoholism (Ref. $=$ No) } \\
\hline Yes & 1.38 & 0.29 & 0.119 & 1.09 & 1.76 \\
\hline \multicolumn{6}{|c|}{ Weight (Ref.=Normal) } \\
\hline Under & 1.65 & 0.26 & 0.001 & 1.37 & 1.97 \\
\hline Over & 2.01 & 0.41 & 0.001 & 1.58 & 2.54 \\
\hline Heart rate & 1.02 & 0.005 & 0.002 & 1.01 & 1.02 \\
\hline Systolic BP & 1.01 & 0.003 & 0.002 & 1.006 & 1.01 \\
\hline \multicolumn{6}{|c|}{ Diabetes mellitus $($ Ref. $=$ No) } \\
\hline Yes & 1.49 & 0.27 & 0.031 & 1.20 & 1.84 \\
\hline \multicolumn{6}{|c|}{ Hypertension $($ Ref. $=$ No) } \\
\hline Yes & 2.78 & 0.40 & 0.000 & 2.352 & 3.28 \\
\hline \multicolumn{6}{|c|}{ Coronary Kidney Disease (Ref.=No) } \\
\hline Yes & 2.03 & 0.37 & 0.000 & 1.64 & 2.51 \\
\hline \multicolumn{6}{|c|}{ HIV (Ref.=No) } \\
\hline Yes & 1.95 & 0.30 & 0.000 & 1.63 & 2.33 \\
\hline \multicolumn{6}{|c|}{ Pneumonia $($ Ref. $=$ No) } \\
\hline Yes & 3.33 & 0.70 & 0.000 & 2.62 & 4.25 \\
\hline \multicolumn{6}{|c|}{ Stroke $($ Ref. $=$ No) } \\
\hline Yes & 1.94 & 0.312 & 0.000 & 1.61 & 2.33 \\
\hline \multicolumn{6}{|c|}{ Coronary Artery Disease $($ Ref. $=\mathrm{No})$} \\
\hline Yes & 3.10 & 0.80 & 0.000 & 2.31 & 4.18 \\
\hline \multicolumn{6}{|c|}{ Tuberculosis $($ Ref. $=\mathrm{No})$} \\
\hline Yes & 3.89 & 0.57 & 0.000 & 3.29 & 4.59 \\
\hline
\end{tabular}

"*" represents insignificant variables at $25 \%$ level of significance

All the significant and clinical important variables at $25 \%$ level were included in the bivariable analysis with in a forward stepwise manner with an entry probability 0.05 and removal probability 0.25 . Among the candidate variables considered for building multivariable Cox, stepwise procedure picked up eighteen variables. Finally, among the independent variables statistically significant and clinical important variables were selected for the multivariable analysis and the Cox proportional hazards model that were not statistically insignificant variables in the multivariable analysis were rejected and the analysis was run until the last best model was obtained with smaller -2 residual likelihood value or AIC\&BIC minimum was better model fit. The final main effect only Multivariable Cox proportional hazard model STATA V. 12 summary results of Coefficients, Hazards ratio, 95\% confidence intervals, standard errors for each variable with their AIC and BIC are presented in table 4. 
Table 4. Final Multivariable Cox regression model for CHF data, GH\&DRH, 2017.

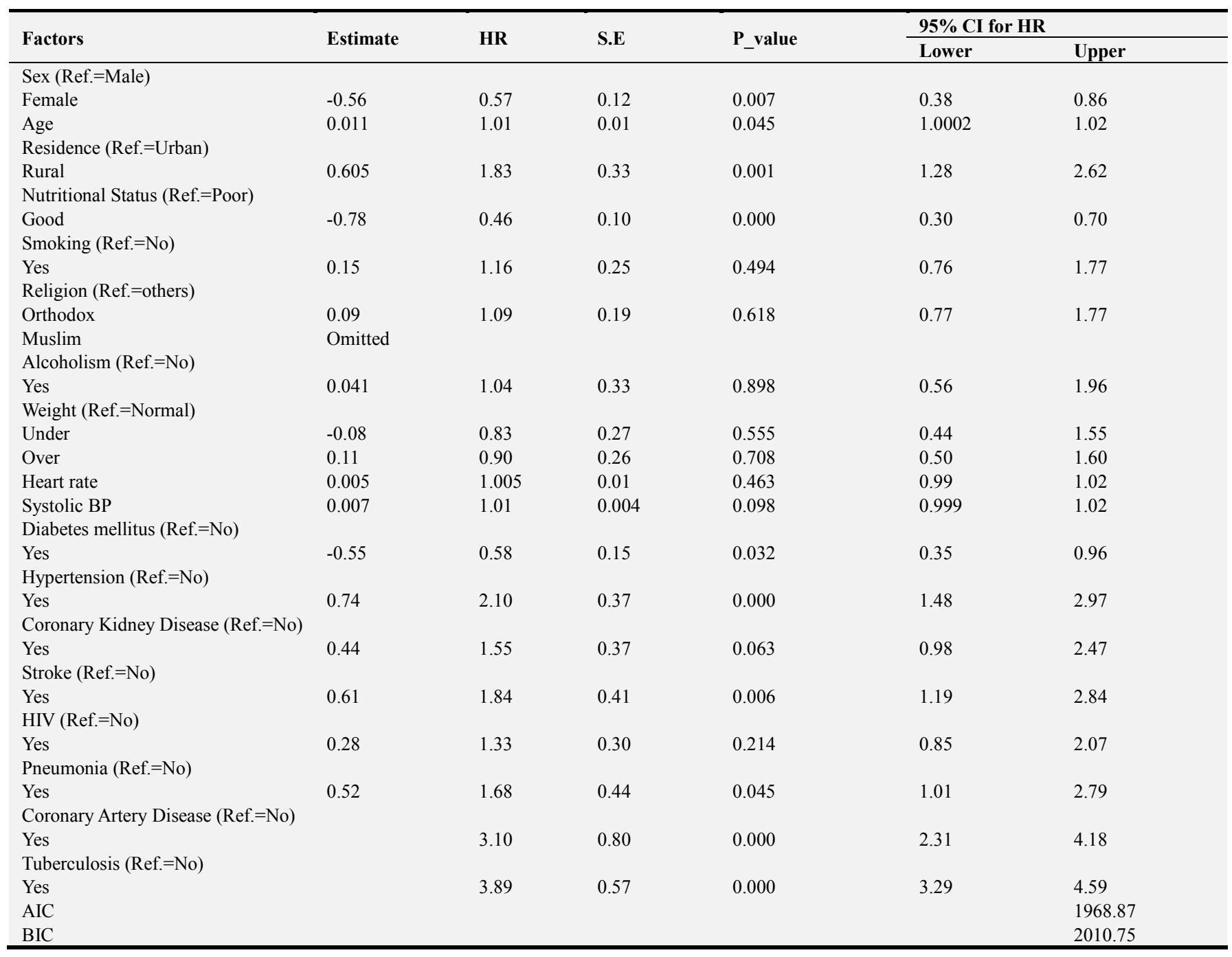

Log likelihood $=-965.8977$, prob. $\operatorname{chi} 2=0.000$, LR chi $(19)=221.62$

\subsection{Parametric Proportional Hazards Model}

The parametric proportional hazards models are the parametric versions of the Cox proportional hazards model. It assumes the baseline hazard function follows a certain distribution and coefficients are estimated by maximum likelihood method, but not in Cox PH models. The results of
Univariable parametric $\mathrm{PH}$ models are presented in table 5. In both models variables significant at $25 \%$ level in the Univariable analysis were taken as candidate variables for their multivariable analysis. Stepwise forward selection procedure was also implemented for these models as used in multivariable Cox model.

Table 5. Results of Univariable Weibull, Exponential and, Log logistic PH model WGH\&DRH, 2017.

\begin{tabular}{|c|c|c|c|c|c|c|c|c|}
\hline \multirow{2}{*}{ Factors } & \multicolumn{4}{|c|}{ Weibull } & \multicolumn{4}{|c|}{ Exponential } \\
\hline & HR & $75 \% \mathrm{CI}$ & Pvalue & S.E & HR & $75 \% \mathrm{CI}$ & Pvalue & S.E \\
\hline \multicolumn{9}{|c|}{ Sex $($ Ref. $=$ No) } \\
\hline Yes & 0.62 & $(0.53,0.73)$ & 0.001 & 0.87 & 0.63 & $0.54,0.74$ & 0.001 & 0.09 \\
\hline Age & 1.03 & $(1.023,1.032)$ & 0.000 & 0.004 & 1.03 & $1.02,1.03$ & 0.000 & 0.01 \\
\hline \multicolumn{9}{|c|}{ Residence (Ref. $=$ Urban $)$} \\
\hline Yes & 1.51 & $1.28,1.78$ & 0.004 & 0.215 & 1.48 & $1.26,1.74$ & 0.005 & 0.21 \\
\hline \multicolumn{9}{|c|}{ Marital Status (Ref.=Divorced) } \\
\hline Single & 0.714 & $0.52,0.98$ & 0.219 & 0.19 & 0.69 & $0.51,0.94$ & 0.174 & 0.19 \\
\hline Married & 0.73 & $0.56,0.94$ & 0.151 & 0.16 & 0.72 & $0.56,0.93$ & 0.140 & 0.16 \\
\hline Windowed & 0.93 & $0.66,1.31$ & 0.808 & 0.27 & 0.93 & $0.66,1.31$ & 0.814 & 0.27 \\
\hline \multicolumn{9}{|c|}{ Educational status (Ref.=No) } \\
\hline Literate & 1.11 & $0.94,1.31$ & 0.486 & 0.16 & 1.10 & $0.93,1.30$ & 0.528 & 0.16 \\
\hline \multicolumn{9}{|c|}{ Alcoholism (Ref.=No) } \\
\hline Yes & 1.56 & $1.23,1.97$ & 0.030 & 0.32 & 1.55 & $1.23,1.96$ & 0.030 & 0.32 \\
\hline
\end{tabular}




\begin{tabular}{|c|c|c|c|c|c|c|c|c|}
\hline \multirow{2}{*}{ Factors } & \multicolumn{4}{|c|}{ Weibull } & \multicolumn{4}{|c|}{ Exponential } \\
\hline & HR & $75 \%$ CI & Pvalue & S.E & HR & $75 \% \mathrm{CI}$ & Pvalue & S.E \\
\hline \multicolumn{9}{|c|}{ Weight (Ref.=Normal) } \\
\hline Under & 0.70 & $0.56,0.88$ & 0.072 & 0.14 & 0.70 & $0.56,0.88$ & 0.072 & 0.14 \\
\hline Over & 0.44 & $0.35,0.56$ & 0.000 & 0.09 & 0.44 & $0.35,0.56$ & 0.000 & 0.09 \\
\hline Hrt & 1.02 & $1.01,1.022$ & 0.001 & 0.005 & 1.01 & $1.01,1.02$ & 0.001 & 0.01 \\
\hline SBP & 1.01 & $1.007,1.013$ & 0.001 & 0.003 & 1.01 & $1.006,1.013$ & 0.001 & 0.003 \\
\hline \multicolumn{9}{|c|}{ Dm (Ref.=No) } \\
\hline $\begin{array}{l}\text { Yes } \\
\text { HTN (Re }\end{array}$ & \multicolumn{7}{|c|}{ HTN (Ref.=No) } & 0.29 \\
\hline $\begin{array}{l}\text { Yes } \\
\text { CKD (Re }\end{array}$ & 2.81 & $2.39,3.30$ & 0.000 & 0.395 & 2.72 & $2.31,3.19$ & 0.000 & 0.38 \\
\hline $\begin{array}{l}\text { Yes } \\
\text { HIV (Ref }\end{array}$ & 2.13 & $1.73,2.62$ & 0.000 & 0.39 & 2.13 & $1.73,2.63$ & 0.000 & 0.39 \\
\hline $\begin{array}{l}\text { Yes } \\
\text { Pneumon }\end{array}$ & 1.85 & $1.56,2.20$ & 0.000 & 0.28 & 1.86 & $1.56,2.21$ & 0.000 & 0.28 \\
\hline $\begin{array}{l}\text { Yes } \\
\text { CAD (Re }\end{array}$ & 3.12 & $2.45,3.96$ & 0.000 & 0.65 & 3.01 & $2.37,3.81$ & 0.000 & 0.62 \\
\hline \multicolumn{9}{|c|}{ Stroke $($ Ref. $=$ No) } \\
\hline Yes & 0.54 & $0.45,0.64$ & 0.000 & 0.09 & 1.89 & $1.57,2.27$ & 0.000 & 0.30 \\
\hline \multicolumn{9}{|c|}{ Tuberculosis $($ Ref. $=$ No) } \\
\hline Yes & 4.18 & $3.55,4.92$ & 0.000 & 0.59 & 4.05 & $3.45,4.76$ & 0.000 & 0.57 \\
\hline
\end{tabular}

Results of multivariable Log logistic main effect model, WGH\&DRH, 2017/2018.

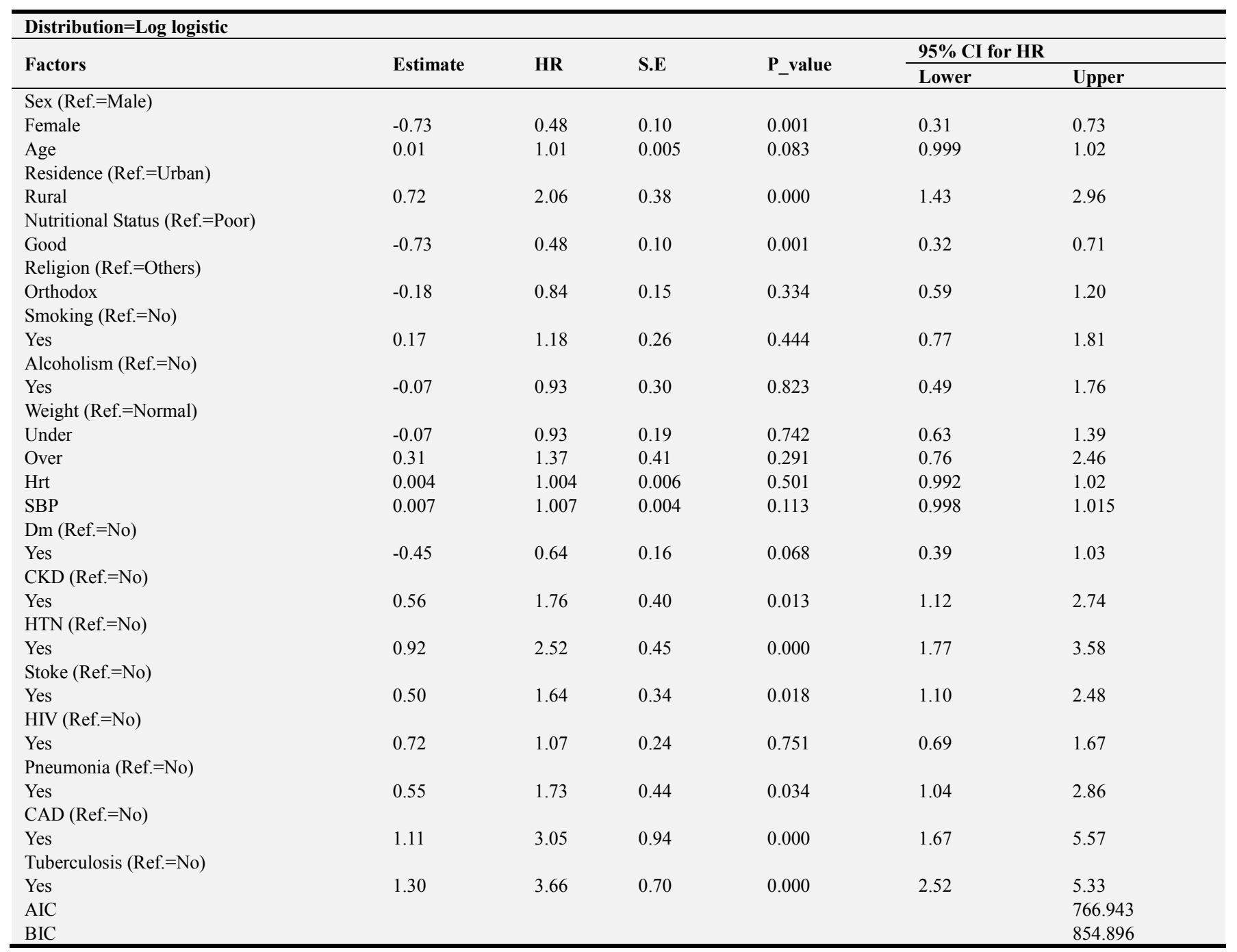

Log likelihood $=-362.47$, LR Chi2 $(19)=239.62 .16 \&$ prob $>$ chi $2=0.0000$ 
As we can seen above univariable analysis summary results table 5 indicates that in all distributions only Marital status and Educational status of a patients are not statistically significant at $25 \%$ level of significant, while all the remaining variables were considered as a candidate for the multivariable models. Therefore the next step is including all significant variables in a model simultaneously and the results of preliminarily final main effect only model are presented in these table.

Likewise from the preliminary main effect multivariate exponential, Log logistic and Weibull $\mathrm{PH}$ models, pick up all variables significance at $5 \%$ for the final model. Statistically significant predictors at 5\% level of significance are sex, Nutritional Status, Presence of Hypertension, Presence of Tuberculosis, Presence of Stroke and Presence of Coronary
Artery Disease as co morbidity are important variables for the decelerate or accelerate of the survival time of the $\mathrm{CHF}$ patient. While Age, Residence, Smoking, Alcoholism, Weight, Religion, Heart Rate, Systolic Blood Pressure, HIV, Presence of Diabetes mellitus and Pneumonia as a co morbidity are insignificant variables. Finally both clinically and statistically important variables with their interaction terms are analyzed together and it can be considered as a final model for each parametric PH models. Actually interaction add in the model by considering their effect have a significant effect even if there is no standards. However iteratively each interaction term importance was assessed at 5\% level of significance. Therefore the final all significant interaction with main effect were modelled and the result was presented in (Tables 6-8).

Table 6. Results of final weibull PH model WGH\&DRH, 2017.

\begin{tabular}{|c|c|c|c|c|c|c|}
\hline \multicolumn{7}{|c|}{ Final Weibull PH model Summary results } \\
\hline \multirow{2}{*}{ Factors } & \multirow{2}{*}{ HR } & \multirow{2}{*}{ S.E } & \multirow{2}{*}{$\mathbf{Z}$} & \multirow{2}{*}{$P_{-}$value } & \multicolumn{2}{|l|}{$95 \%$ CI } \\
\hline & & & & & Lower & Upper \\
\hline \multicolumn{7}{|l|}{ Sex (Ref.=Male) } \\
\hline Female & 0.59 & 0.14 & -2.23 & 0.026 & 0.371 & 0.940 \\
\hline Age & 1.04 & 0.01 & 4.40 & 0.000 & 1.02 & 1.05 \\
\hline \multicolumn{7}{|c|}{ Residence (Ref.=Urban) } \\
\hline $\begin{array}{l}\text { Rural } \\
\text { Nutritional Status }\end{array}$ & 1.74 & 0.33 & 2.94 & 0.003 & 1.20 & 2.53 \\
\hline $\begin{array}{l}\text { Nutritional status (I } \\
\text { Good }\end{array}$ & \multicolumn{6}{|c|}{ Nutritional Status (Ref.=Poor) } \\
\hline \multicolumn{7}{|c|}{ Smoking status $($ Ref. $=$ No) } \\
\hline \multicolumn{7}{|c|}{ Alcoholism (Ref.=No) } \\
\hline Yes & 1.24 & 0.38 & 0.70 & 0.482 & 0.68 & 2.27 \\
\hline Baseline Heart rate & 1.005 & 0.006 & 0.79 & 0.431 & 0.993 & 1.02 \\
\hline Sbp & 1.01 & 0.005 & 2.08 & 0.037 & 1.001 & 1.02 \\
\hline \multicolumn{7}{|l|}{ Dm (Ref.=No) } \\
\hline Yes & 0.39 & 0.12 & -2.95 & 0.003 & 0.205 & 0.73 \\
\hline \multicolumn{7}{|l|}{ CAD (Ref.=No) } \\
\hline Yes & 33.7 & 43.18 & 2.75 & 0.006 & 2.73 & 425.28 \\
\hline \multicolumn{7}{|c|}{ Coronary kidney disease $(\mathrm{Ref} .=\mathrm{No})$} \\
\hline \multirow{2}{*}{\multicolumn{7}{|c|}{ HIV (Ref.=No) }} \\
\hline & & & & & & \\
\hline Yes & 1.23 & 0.30 & 1.13 & 0.257 & 0.83 & 2.04 \\
\hline \multicolumn{7}{|l|}{ HTN (Ref.=No) } \\
\hline Yes & 1.43 & 0.281 & 1.82 & 0.069 & 0.973 & 2.51 \\
\hline \multicolumn{7}{|l|}{ Stoke (Ref.=No) } \\
\hline \multicolumn{6}{|l|}{ Pneumonia (Ref.=No) } & 1.83 \\
\hline $\begin{array}{l}\text { Yes } \\
\text { Tuberculosis (Ref.= }\end{array}$ & 1.91 & 0.51 & 2.43 & 0.015 & 1.13 & 3.23 \\
\hline Yes & 101.31 & 76.89 & 6.11 & 0.000 & 23.06 & 447.8 \\
\hline \multicolumn{7}{|l|}{ Tb*Age (Ref.=No) } \\
\hline Yes*Age & 0.96 & 0.012 & -3.69 & 0.000 & 0.934 & 0.980 \\
\hline \multicolumn{7}{|l|}{ CAD*Age (Ref.=No) } \\
\hline Yes*Age & 0.96 & 0.02 & -2.04 & 0.041 & 0.92 & 0.998 \\
\hline \multicolumn{7}{|c|}{ Nut $($ Ref. $=$ No $) * T b($ Ref. $=$ No $)$} \\
\hline Yes & 0.37 & 0.15 & -2.5 & 0.012 & 0.17 & 0.81 \\
\hline \multicolumn{7}{|c|}{ Dm $(\text { Ref. }=\text { No })^{*}$ HTN $($ Ref. $=$ No $)$} \\
\hline Yes & 3.61 & 1.58 & 2.92 & 0.003 & 1.53 & 8.54 \\
\hline Constant & 0.00007 & 0.0001 & -11.79 & 0.000 & 0.000014 & 0.00033 \\
\hline$/ \ln \_p$ & 0.31 & 0.06 & 5.32 & 0.000 & 0.19 & 0.42 \\
\hline $\mathrm{P}$ & 1.36 & 0.08 & & 1.21 & 1.52 & \\
\hline $1 / \mathrm{p}$ & 0.73 & 0.04 & & 0.66 & 0.82 & \\
\hline AIC & & & & & & 735.4757 \\
\hline BIC & & & & & & 827.6175 \\
\hline
\end{tabular}

Log likelihood $=-345.7385$ LR chi2 $(21)=273.09$ Prob $>$ chi $2=0.0000$ 


$$
R^{2}=1-\left\{\exp \left[\frac{2}{486}(-482.2827+345.7379)\right]\right\}=50.01 \%
$$

Table 7. Results of final Log logistic PH model WGH \& DRH, 2017.

\begin{tabular}{|c|c|c|c|c|c|c|}
\hline \multicolumn{7}{|c|}{ Final Log logistic PH model Summary results } \\
\hline \multirow{2}{*}{ Factors } & \multirow{2}{*}{ HR } & \multirow{2}{*}{ S.E } & \multirow{2}{*}{$\mathbf{Z}$} & \multirow{2}{*}{ P_value } & \multicolumn{2}{|l|}{$95 \% \mathrm{CI}$} \\
\hline & & & & & Lower & Upper \\
\hline \multicolumn{7}{|l|}{ Sex (Ref.=Male) } \\
\hline Female & 0.46 & 0.18 & 2.55 & 0.011 & 0.105 & 0.81 \\
\hline Age & -0.025 & 0.01 & -3.73 & 0.000 & -0.04 & -0.012 \\
\hline \multicolumn{7}{|c|}{ Residence (Ref. $=$ Urban) } \\
\hline \multicolumn{6}{|c|}{ Nutritional Status (Ref.=Poor) } & 0.134 \\
\hline $\begin{array}{l}\text { Good } \\
\text { Smoking status (Ref }\end{array}$ & 0.92 & 0.21 & 4.45 & 0.000 & 0.52 & 1.33 \\
\hline \multicolumn{6}{|c|}{ Alcoholism (Ref.=No) } & 0.67 \\
\hline Yes & 0.097 & 0.26 & 0.37 & 0.709 & -0.414 & 0.61 \\
\hline Baseline Heart rate & -0.003 & 0.006 & -0.49 & 0.627 & -0.014 & 0.009 \\
\hline SBp & -0.006 & 0.004 & -1.67 & 0.095 & -0.013 & 0.001 \\
\hline \multicolumn{7}{|l|}{$\operatorname{Dm}(\mathrm{Ref} .=\mathrm{No})$} \\
\hline \multicolumn{6}{|l|}{ CAD (Ref.=No) } & 0.88 \\
\hline $\begin{array}{l}\text { Yes } \\
\text { Coronary kidney dis }\end{array}$ & -3.78 & 0.886 & -4.26 & 0.000 & -5.52 & -2.04 \\
\hline \multicolumn{7}{|l|}{ HIV (Ref.=No) } \\
\hline \multicolumn{6}{|l|}{ HTN (Ref.=No) } & 0.018 \\
\hline \multicolumn{6}{|l|}{ Stoke $($ Ref. $=$ No) } & -0.16 \\
\hline \multicolumn{6}{|l|}{ Pneumonia (Ref.=No) } & 0.292 \\
\hline $\begin{array}{l}\text { Yes } \\
\text { Tuberculosis (Ref.=1 }\end{array}$ & -0.335 & 0.235 & -1.43 & 0.153 & -0.795 & 0.125 \\
\hline \multicolumn{6}{|l|}{ Tb*Age (Ref.=No) } & -2.82 \\
\hline $\begin{array}{l}\text { Yes*Age } \\
\text { CAD*Age (Ref. }=\text { No }\end{array}$ & 0.06 & 0.01 & 5.4 & 0.000 & 0.036 & 0.077 \\
\hline \multicolumn{6}{|c|}{ Nut $($ Ref. $=$ No)*Tb $($ Ref. $=$ No) } & 0.08 \\
\hline \multicolumn{7}{|c|}{ Dm $($ Ref. $=$ No $) * H T N($ Ref. $=$ No $)$} \\
\hline Yes & -0.55 & 0.417 & -1.32 & 0.188 & -1.37 & 0.27 \\
\hline Constant & 5.58 & 0.62 & -1.32 & 0.000 & 4.36 & 6.79 \\
\hline /ln_gamma & -0.55 & 0.59 & 9.01 & 0.000 & -0.66 & -0.434 \\
\hline Gamma & 0.58 & 0.034 & & & 0.514 & 0.65 \\
\hline AIC & & & & & & 758.1743 \\
\hline BIC & & & & & & 850.3162 \\
\hline
\end{tabular}

Log likelihood $=-357.08717$ LR chi2 $(21)=269.25$ Prob $>$ chi2 $=0.0000$

$$
R^{2}=1-\left\{\exp \left[\frac{2}{486}(-491.713+357.0872)\right]\right\}=57.34 \%
$$

\begin{tabular}{|c|c|c|c|c|c|c|}
\hline \multicolumn{7}{|c|}{ Final exponential PH model Summary results } \\
\hline \multirow{2}{*}{ Factors } & \multirow{2}{*}{ HR } & \multirow{2}{*}{ S.E } & \multirow{2}{*}{$\mathbf{Z}$} & \multirow{2}{*}{ P_value } & \multicolumn{2}{|l|}{$95 \% \mathrm{CI}$} \\
\hline & & & & & Lower & Upper \\
\hline \multicolumn{7}{|c|}{ Sex (Ref.=Male) } \\
\hline Female & 0.68 & 0.156 & -1.68 & 0.093 & 0.436 & 1.027 \\
\hline Age & 1.034 & 0.008 & 4.07 & 0.000 & 1.017 & 1.05 \\
\hline \multicolumn{7}{|c|}{ Residence (Ref.=Urban) } \\
\hline Rural & 1.478 & 0.27 & 2.11 & 0.035 & 1.03 & 2.13 \\
\hline \multicolumn{7}{|c|}{ Nutritional Status (Ref.=Poor) } \\
\hline Good & 3.09 & 0.865 & 4.03 & 0.000 & 1.786 & 5.349 \\
\hline
\end{tabular}

Table 8. Results of final exponential PH model WGH \& DRH, 2017. 


\begin{tabular}{|c|c|c|c|c|c|c|}
\hline \multicolumn{7}{|c|}{ Final exponential PH model Summary results } \\
\hline \multirow{2}{*}{ Factors } & \multirow{2}{*}{ HR } & \multirow{2}{*}{ S.E } & \multirow{2}{*}{$\mathbf{Z}$} & \multirow{2}{*}{ P_value } & \multicolumn{2}{|l|}{$95 \% \mathrm{CI}$} \\
\hline & & & & & Lower & Upper \\
\hline \multicolumn{7}{|c|}{ Smoking status (Ref. $=$ No) } \\
\hline Yes & 0.956 & 0.202 & -0.21 & 0.831 & 0.631 & 1.45 \\
\hline \multicolumn{7}{|c|}{ Alcoholism (Ref.=No) } \\
\hline Yes & 1.088 & 0.326 & 0.28 & 0.779 & 0.604 & 1.96 \\
\hline Baseline Hear trate & 1.005 & 0.006 & 0.90 & 0.369 & 0.994 & 1.02 \\
\hline Sbp & 1.008 & 0.0045 & 1.71 & 0.088 & 0.999 & 1.02 \\
\hline \multicolumn{7}{|l|}{ Dm $($ Ref. $=\mathrm{No})$} \\
\hline Yes & 0.534 & 0.168 & -2.00 & 0.046 & 0.29 & 0.989 \\
\hline \multicolumn{7}{|l|}{ CAD (Ref. $=$ No $)$} \\
\hline Yes & 19.99 & 23.29 & 2.57 & 0.010 & 2.04 & 196.08 \\
\hline \multicolumn{7}{|c|}{ Coronary kidney disease $($ Ref. $=$ No) } \\
\hline Yes & 1.214 & 0.298 & 0.79 & 0.429 & 0.750 & 1.965 \\
\hline \multicolumn{7}{|l|}{ HIV (Ref.=No) } \\
\hline Yes & 1.35 & 0.30 & 1.37 & 0.17 & 0.878 & 2.09 \\
\hline \multicolumn{7}{|l|}{ HTN (Ref.=No) } \\
\hline Yes & 1.45 & 0.298 & 1.91 & 0.056 & 0.99 & 2.115 \\
\hline \multicolumn{7}{|l|}{ Stoke $($ Ref. $=$ No) } \\
\hline Yes & 1.21 & 0.282 & 0.82 & 0.414 & 0.766 & 1.965 \\
\hline \multicolumn{7}{|c|}{ Pneumonia $($ Ref. $=$ No) } \\
\hline Yes & 1.67 & 0.434 & 1.98 & 0.048 & 1.004 & 2.78 \\
\hline \multicolumn{7}{|c|}{ Tuberculosis $($ Ref. $=$ No) } \\
\hline Yes & 75.03 & 55.28 & 5.86 & 0.000 & 17.7 & 317.98 \\
\hline \multicolumn{7}{|l|}{$\mathrm{Tb}^{*}$ Age $($ Ref. $=\mathrm{No})$} \\
\hline Yes*Age & 0.96 & 0.011 & -3.41 & 0.001 & 0.94 & 0.983 \\
\hline \multicolumn{7}{|l|}{ CAD*Age (Ref. $=$ No) } \\
\hline Yes*Age & 0.96 & 0.019 & -1.87 & 0.062 & 0.926 & 1.002 \\
\hline \multicolumn{7}{|c|}{ Nut (Ref.=No)*Tb $($ Ref. $=$ No) } \\
\hline Yes & 0.32 & 0.124 & -2.94 & 0.003 & 0.149 & 0.683 \\
\hline \multicolumn{7}{|c|}{ Dm $($ Ref. $=$ No)*HTN $($ Ref. $=$ No) } \\
\hline Yes & 2.59 & 1.104 & 2.33 & 0.026 & 1.123 & 5.974 \\
\hline Constant & 0.0003 & 0.0002 & -11.10 & 0.000 & 0.0001 & 0.001 \\
\hline AIC & & & & & & 758.6276 \\
\hline BIC & & & & & & 846.5812 \\
\hline
\end{tabular}

Log likelihood $=-358.3138$ LR chi2 $(20)=249.59$ Prob $>$ chi $2=0.0000$

$$
R^{2}=1-\left\{\exp \left[\frac{2}{486}(-483.1094+358.3138)\right]\right\}=87.37 \%
$$

From the above final three parametric PH model exponential have better performance to explain the effect of covariates on the survival time of patient with CHF since it have high $\mathrm{R}^{2}$ type statistic which is it accounts around $87.37 \%$. We can take is as thee alternative model for Cox model even if the assumption is violated.

\subsection{AFT Model Results}

The AFT model which is another alternative of the Cox PH model when the $\mathrm{PH}$ assumption is violate. It can be used to express the magnitude of effect in a more accessible way in terms of difference between covariates in survival time. We fitted the dataset using exponential, Weibull and log-logistic AFT model. Similarly we done the same procedure for AFT models like so far in parametric Cox proportional models. In all models variables significant at $25 \%$ level in the Univariable analysis were taken as candidate variables for their multivariable analysis. Finally all variables in a main effect model and it's interaction term significant at $5 \%$ with a stepwise forward selection procedure was also implemented and reported in (Tables 9-11).

Table 9. Results of final Log logistic AFT model WGH \& DRH, 2017.

\begin{tabular}{|c|c|c|c|c|c|c|}
\hline \multicolumn{7}{|c|}{ Final Log logistic AFT model Summary results } \\
\hline \multirow{2}{*}{ Factors } & \multirow{2}{*}{ TR } & \multirow{2}{*}{ S.E } & \multirow{2}{*}{$\mathbf{Z}$} & \multirow{2}{*}{ P_value } & \multicolumn{2}{|l|}{$95 \%$ CI } \\
\hline & & & & & Lower & Upper \\
\hline Sex (Ref.=Male) & & & & & & \\
\hline Female & 1.285 & 0.137 & 2.35 & 0.019 & 1.043 & 1.583 \\
\hline Age & 0.965 & 0.004 & -8.61 & 0.000 & 0.957 & 0.973 \\
\hline
\end{tabular}




\begin{tabular}{|c|c|c|c|c|c|c|}
\hline \multicolumn{7}{|c|}{ Final Log logistic AFT model Summary results } \\
\hline \multirow{2}{*}{ Factors } & \multirow{2}{*}{ TR } & \multirow{2}{*}{ S.E } & \multirow{2}{*}{$\mathbf{Z}$} & \multirow{2}{*}{ P_value } & \multicolumn{2}{|l|}{$95 \% \mathrm{CI}$} \\
\hline & & & & & Lower & Upper \\
\hline \multicolumn{7}{|c|}{ Residence (Ref.=Urban) } \\
\hline Rural & 1.167 & 0.117 & 1.54 & $0.124 *$ & 0.958 & 1.421 \\
\hline \multicolumn{7}{|c|}{ Nutritional Status $($ Ref. $=$ Good $)$} \\
\hline Poor & 0.64 & 0.784 & -3.64 & 0.000 & 0.504 & 0.835 \\
\hline \multicolumn{7}{|c|}{ Smoking status (Ref.=No) } \\
\hline Yes & 0.669 & 0.090 & -2.97 & 0.003 & 0.513 & 0.872 \\
\hline \multicolumn{7}{|c|}{ Alcoholism (Ref.=No) } \\
\hline Yes & 1.677 & 0.268 & 3.23 & 0.001 & 1.226 & 2.295 \\
\hline \multicolumn{7}{|l|}{$\operatorname{Dm}(\mathrm{Ref} .=\mathrm{No})$} \\
\hline Yes & 0.363 & 0.063 & -5.79 & 0.000 & 0.268 & 0.512 \\
\hline Baseline Heart rate & 0.999 & 0.003 & -0.33 & $0.745^{*}$ & 0.992 & 1.006 \\
\hline SBP & 0.999 & 0.002 & -0.37 & $0.709^{*}$ & 0.995 & 1.003 \\
\hline \multicolumn{7}{|l|}{ CAD (Ref.=No) } \\
\hline Yes & 0.201 & 0.110 & -2.94 & 0.003 & 0.069 & 0.587 \\
\hline \multicolumn{7}{|c|}{ Coronary kidney disease $(\operatorname{Ref} .=\mathrm{No})$} \\
\hline Yes & 0.714 & 0.099 & -2.42 & 0.016 & 0.543 & 0.938 \\
\hline \multicolumn{7}{|l|}{ HIV (Ref.=No) } \\
\hline Yes & 0.841 & 0.102 & -1.44 & $0.151^{*}$ & 0.663 & 1.065 \\
\hline \multicolumn{7}{|l|}{ HTN (Ref.=No) } \\
\hline Yes & 0.789 & 0.079 & -2.35 & 0.019 & 0.648 & 0.962 \\
\hline \multicolumn{7}{|l|}{ Stoke $($ Ref. $=$ No) } \\
\hline Yes & 0.805 & 0.098 & -1.77 & $0.076^{*}$ & 0.634 & 1.023 \\
\hline \multicolumn{7}{|c|}{ Pneumonia $($ Ref. $=$ No) } \\
\hline Yes & 1.064 & 0.161 & 0.41 & $0.682 *$ & 0.791 & 1.431 \\
\hline \multicolumn{7}{|c|}{ Tuberculosis $($ Ref. $=$ No $)$} \\
\hline Yes & 0.029 & 0.012 & -8.23 & 0.000 & 0.012 & 0.067 \\
\hline \multicolumn{7}{|l|}{ Tb*Age (Ref.=No) } \\
\hline Yes*Age & 1.041 & 0.007 & 5.90 & 0.000 & 1.027 & 1.054 \\
\hline \multicolumn{7}{|l|}{ CAD*Age $($ Ref. $=$ No $)$} \\
\hline Yes*Age & 1.021 & 0.009 & 2.23 & 0.026 & 1.002 & 1.040 \\
\hline \multicolumn{7}{|c|}{ Nut (Ref.=No)*Tb (Ref.=No) } \\
\hline Yes & 2.227 & 0.447 & 4.03 & 0.000 & 1.508 & 3.287 \\
\hline \multicolumn{7}{|c|}{ Dm $($ Ref. $=$ No)*HTN $($ Ref. $=$ No) } \\
\hline Yes & 2.79 & 0.703 & 4.07 & 0.000 & 1.703 & 4.573 \\
\hline Time*Age & 1.001 & .00007 & 18.53 & 0.000 & 1.0011 & 1.0014 \\
\hline Constant term & 78.396 & 30.473 & 11.22 & 0.000 & 36.596 & 167.941 \\
\hline /ln_gamma & -1.067 & 0.058 & -18.40 & 0.000 & -1.180 & -0.953 \\
\hline Gamma & 0.344 & 0.020 & & & 0.307 & 0.385 \\
\hline AIC & & & & & & 542.722 \\
\hline BIC & & & & & & 639.0521 \\
\hline
\end{tabular}

Log likelihood $=-248.361$ LR chi2 $(21)=486.70$ Prob $>$ chi2 $=0.0000$

$$
R^{2}=1-\left\{\exp \left[\frac{2}{486}(-491.713-(-248.361))\right]\right\}=63.27 \%
$$

Table 10. Results of final Weibull AFT model WGH \& DRH, 2017.

\begin{tabular}{|c|c|c|c|c|c|c|}
\hline \multicolumn{7}{|c|}{ Final Weibull AFT model Summary results } \\
\hline \multirow{2}{*}{ Factors } & \multirow{2}{*}{ TR } & \multirow{2}{*}{ S.E } & \multirow{2}{*}{$\mathbf{Z}$} & \multirow{2}{*}{ P_value } & \multicolumn{2}{|l|}{$95 \% \mathrm{CI}$} \\
\hline & & & & & Lower & Upper \\
\hline \multicolumn{7}{|l|}{ Sex (Ref.=Male) } \\
\hline Female & 1.137 & 0.111 & 1.31 & $0.190 *$ & 0.938 & 1.377 \\
\hline Age & 0.962 & 0.004 & -9.71 & 0.000 & 0.954 & 0.969 \\
\hline Residence (Ref. $=$ Ur & & & & & & \\
\hline $\begin{array}{l}\text { Rural } \\
\text { Nutritional Status ( }\end{array}$ & 1.237 & 0.112 & 2.34 & 0.019 & 1.035 & 1.478 \\
\hline $\begin{array}{l}\text { Poor } \\
\text { Smoking status (Re }\end{array}$ & 0.582 & 0.073 & -4.33 & 0.000 & 0.456 & 0.744 \\
\hline $\begin{array}{l}\text { Yes } \\
\text { Alcoholism (Ref. }=\mathrm{N}\end{array}$ & 0.774 & 0.071 & -2.78 & 0.005 & 0.646 & 0.927 \\
\hline $\begin{array}{l}\text { Yes } \\
\text { Dm (Ref.=No) }\end{array}$ & 1.394 & 0.179 & 2.59 & 0.010 & 1.084 & 1.793 \\
\hline Yes & 0.490 & 0.072 & -4.85 & 0.000 & 0.367 & 0.653 \\
\hline Baseline Heart rate & 0.999 & 0.003 & -0.33 & $0.745^{*}$ & 0.992 & 1.006 \\
\hline
\end{tabular}




\begin{tabular}{|c|c|c|c|c|c|c|}
\hline \multicolumn{7}{|c|}{ Final Weibull AFT model Summary results } \\
\hline \multirow{2}{*}{ Factors } & \multirow{2}{*}{ TR } & \multirow{2}{*}{ S.E } & \multirow{2}{*}{$\mathbf{Z}$} & \multirow{2}{*}{$P_{\text {_value }}$} & \multicolumn{2}{|l|}{ 95\%CI } \\
\hline & & & & & Lower & Upper \\
\hline $\begin{array}{l}\text { SBP } \\
\text { CAD (Ref.=No }\end{array}$ & 0.999 & 0.002 & -0.37 & $0.709^{*}$ & 0.995 & 1.003 \\
\hline $\begin{array}{l}\text { Yes } \\
\text { Coronary kidne }\end{array}$ & 0.276 & 0.141 & -2.52 & 0.012 & 0.101 & 0.752 \\
\hline $\begin{array}{l}\text { Yes } \\
\text { HIV (Ref.=No) }\end{array}$ & 0.81 & 0.095 & -1.79 & $0.074 *$ & 0.64 & 1.02 \\
\hline $\begin{array}{l}\text { Yes } \\
\text { HTN (Ref. }=\text { No }\end{array}$ & 1.014 & 0.101 & 0.14 & $0.891^{*}$ & 0.834 & 1.233 \\
\hline $\begin{array}{l}\text { Yes } \\
\text { Stoke }(\text { Ref. }=\mathrm{No}\end{array}$ & 0.789 & 0.079 & -2.35 & 0.019 & 0.648 & 0.962 \\
\hline $\begin{array}{l}\text { Yes } \\
\text { Pneumonia (Re }\end{array}$ & 0.799 & 0.073 & -2.45 & 0.014 & 0.668 & 0.956 \\
\hline $\begin{array}{l}\text { Yes } \\
\text { Tuberculosis (R }\end{array}$ & 1.250 & 0.144 & 1.95 & $0.052 *$ & 0.98 & 1.566 \\
\hline $\begin{array}{l}\text { Yes } \\
\mathrm{Tb}^{*} \text { Age (Ref.= }\end{array}$ & 0.103 & 0.036 & -6.52 & 0.000 & 0.052 & 0.204 \\
\hline $\begin{array}{l}\text { Yes*Age } \\
\text { CAD*Age (Ref }\end{array}$ & 1.021 & 0.0055 & 3.83 & 0.000 & 1.010 & 1.032 \\
\hline $\begin{array}{l}\text { Yes*Age } \\
\text { Nut (Ref.=No) }\end{array}$ & 1.018 & 0.009 & 2.05 & 0.041 & 1.001 & 1.036 \\
\hline $\begin{array}{l}\text { Yes } \\
\text { Dm }(\text { Ref. }=\text { No) }\end{array}$ & 2.05 & 0.365 & 4.04 & 0.000 & 1.448 & 2.908 \\
\hline Yes & 2.18 & 0.45 & 3.78 & 0.000 & 1.455 & 3.268 \\
\hline Time*Age & 1.001 & .00007 & 16.49 & 0.000 & 1.001 & 1.002 \\
\hline Constant term & 125.078 & 43.931 & 13.75 & 0.000 & 62.836 & 248.97 \\
\hline$/ \ln \_p$ & 0.824 & 0.06 & 13.8 & 0.000 & 0.707 & 0.941 \\
\hline $\mathrm{P}$ & 2.279 & 0.136 & & & 2.028 & 2.562 \\
\hline $1 / \mathrm{p}$ & 0.439 & 0.026 & & & 0.390 & 0.493 \\
\hline AIC & & & & & & 532.1867 \\
\hline BIC & & & & & & 628.5167 \\
\hline
\end{tabular}

Log likelihood $=-243.09333$ LR chi2 $(21)=478.38$ Prob $>$ chi2 $=0.0000$

$$
R^{2}=1-\left\{\exp \left[\frac{2}{486}(-(-243.09333)-(-(-532.1867)))\right]\right\}=69.58 \%
$$

Table 11. Results of final exponential AFT model WGH \& DRH, 2017.

\begin{tabular}{|c|c|c|c|c|c|c|}
\hline \multicolumn{7}{|c|}{ Final exponential AFT model Summary results } \\
\hline \multirow{2}{*}{ Factors } & \multirow{2}{*}{ TR } & \multirow{2}{*}{ S.E } & \multirow{2}{*}{$\mathbf{Z}$} & \multirow{2}{*}{$P_{-}$value } & \multicolumn{2}{|l|}{$95 \%$ CI } \\
\hline & & & & & Lower & Upper \\
\hline \multicolumn{7}{|l|}{ Sex (Ref.=Male) } \\
\hline Female & 1.081 & 0.228 & 0.37 & 0.712 & 0.715 & 1.635 \\
\hline Age & 0.948 & 0.008 & -6.49 & 0.000 & 0.932 & 0.963 \\
\hline \multicolumn{7}{|c|}{ Residence (Ref.=Urban) } \\
\hline \multicolumn{7}{|c|}{ Nutritional Status (Ref.=Good) } \\
\hline \multicolumn{7}{|c|}{ Smoking status $($ Ref. $=$ No) } \\
\hline \multicolumn{7}{|c|}{ Alcoholism (Ref.=No) } \\
\hline Yes & 1.493 & 0.425 & 1.41 & $0.159^{*}$ & 0.855 & 2.610 \\
\hline Baseline Heart rate & 0.993 & 0.0061 & -1.16 & $0.244^{*}$ & 0.981 & 1.005 \\
\hline SBp & 0.999 & 0.0043 & -0.12 & $0.905^{*}$ & 0.991 & 1.008 \\
\hline $\begin{array}{l}\text { Dm }(\text { Ref.=No) } \\
\text { Yes } \\
\text { CAD (Ref.=No) }\end{array}$ & 0.428 & 0.137 & -2.65 & 0.008 & 0.228 & 0.802 \\
\hline \multicolumn{7}{|c|}{ Coronary kidney disease $($ Ref. $=$ No) } \\
\hline \multicolumn{7}{|l|}{ HIV (Ref.=No) } \\
\hline $\begin{array}{l}\text { Yes } \\
\text { HTN (Ref.=No) }\end{array}$ & 0.81 & 0.169 & -1.01 & $0.311^{*}$ & 0.536 & 1.219 \\
\hline $\begin{array}{l}\text { Yes } \\
\text { Stoke }(\text { Ref. }=\text { No) }\end{array}$ & 0.661 & 0.126 & -2.16 & 0.031 & 0.455 & 0.962 \\
\hline
\end{tabular}




\begin{tabular}{|c|c|c|c|c|c|c|}
\hline \multicolumn{7}{|c|}{ Final exponential AFT model Summary results } \\
\hline \multirow{2}{*}{ Factors } & \multirow{2}{*}{ TR } & \multirow{2}{*}{ S.E } & \multirow{2}{*}{$\mathbf{Z}$} & \multirow{2}{*}{$\mathbf{P}_{-}$value } & \multicolumn{2}{|l|}{$95 \% \mathrm{CI}$} \\
\hline & & & & & Lower & Upper \\
\hline $\begin{array}{l}\text { Yes } \\
\text { Pneumonia (R }\end{array}$ & 0.615 & 0.128 & -2.33 & 0.020 & 0.409 & 0.926 \\
\hline $\begin{array}{l}\text { Yes } \\
\text { Tuberculosis }\end{array}$ & 1.01 & 0.260 & 0.05 & $0.956^{*}$ & 0.613 & 1.678 \\
\hline $\begin{array}{l}\text { Yes } \\
\text { Tb*Age (Ref. }\end{array}$ & 0.014 & 0.010 & -5.81 & 0.000 & 0.003 & 0.059 \\
\hline $\begin{array}{l}\text { Yes*Age } \\
\text { CAD*Age (Re }\end{array}$ & 1.039 & 0.012 & 3.33 & 0.001 & 1.016 & 1.059 \\
\hline $\begin{array}{l}\text { Yes*Age } \\
\text { Nut (Ref.=No) }\end{array}$ & 1.022 & 0.019 & 1.19 & $0.236^{*}$ & 0.986 & 1.060 \\
\hline $\begin{array}{l}\text { Yes } \\
\text { Dm (Ref.=No) }\end{array}$ & 4.097 & 1.585 & 3.64 & 0.000 & 1.919 & 8.746 \\
\hline Yes & 2.335 & 1.02 & 1.93 & 0.054 & 0.987 & 5.526 \\
\hline Time*Age & 1.001 & .0001 & 9.42 & 0.000 & 1.001 & 1.002 \\
\hline Constant term & 1338.39 & 996.71 & 9.62 & 0.000 & 310.95 & 5760.724 \\
\hline AIC & & & & & & 673.8928 \\
\hline BIC & & & & & & 666.0346 \\
\hline
\end{tabular}

Log likelihood $=-314.9464$ LR chi2 $(21)=336.33$ Prob $>$ chi2 $=0.0000$

$$
R^{2}=1-\left\{\exp \left[\frac{2}{486}(-(-483.1094)-(-(-314.9464)))\right]\right\}=49.94 \%
$$

\subsection{Discussion}

For this study, based on AIC, weibull AFT model were found to be the better among all semi and parametric models. In our case the weibull AFT model produced a consistence a far from zero parameter as compared to the other parametric model as well as Cox PH suggesting that the exponential PH model was better than the rest parametric as well as semi parametric model.

Age is an important demographic variable that affects the Lifespan of patients with CHF. As the age of the patient increases in years $(\mathrm{TR}=0.962)$ the lifespan of $\mathrm{CHF}$ patients were found to be prolonged. Our finding was similar with the previous study [14]. On the other hand study suggest that age were not significantly associated with CHF complications [11, 15]. In this study, the weibull AFT model as compared to the above studies might have contributed for the statistically significant association between the age and time to event. One of the other predictor variable was the presence of coronary kidney disease as a co morbidity which is not statistically significant. This study is not consistent with other studies suggests that more than $40 \%$ of HF patients have CKD and worsens their survival time [16].

A meta-analysis of 8 studies conducted in patients with CKD (stages 3-5) and CHF showed that beta blocker therapy lowered all-cause and cardiovascular mortality with an increased risk of bradycardia and hypotension [17]. They also suggests that older patients having CKD as a co morbidity accelerating the mortality of patients with CHF. In this study, the weibull AFT model and the study design as well as the number of subjects as compared to the above studies might be the statistically insignificant association between the presence of coronary kidney disease and time to event. Additionally May be physicians were not evaluated well even if it needs further study. Place of residence of the patients with CHF were found statistically significant with a probability value of $(\mathrm{p}=0.019)$. Based on the multivariate Weibull AFT model result patients with CHF who lived rural area were 1.24 times longer live than urban patients. This might be due to the different poisoning chemicals from the vehicles, industries, and suffocations. Actually there is no enough research which is conducted on the relationship between place of residences and CHF. Malnutrition were found statistically significant $(\mathrm{p}=0.000)$. CHF patients who do not intake good nutrition can decelerate their life by 0.582 than patients who intake of nutrationous food. Therefore intake of good food prolong the life of CHF patients. This study is confirmed with a study on nutrition using Cox $\mathrm{PH}$ model suggests that patients had CHF had intake of poor diet was fastening mortality patients $(\mathrm{p}<0.001)$. In other words patients with heart failure being malunutrishes had higher mortality $[1,18]$.

Similarly smoking were found statistically significant at a probability value of $(p=0.005)$. Hence, smoker had shorter life span than non smokers (time ratio=0.7724). In other words smoking were accelerating the hazard of death of the patient with CHF. This study is confirmed with the previous report [19]. It suggests that smoking status at baseline for a one year survival study did not show any significant effect on the outcomes of patients with CHF. However, the study also suggests that smoking status was significantly associated with HF patients' for 1-year health status. Meaning smoking long time accelerate the mortality.

The other predictor variable under this study were alcoholism which is an important variable for the accelerate or decelerate of the survival time of patients with CHF. However this study indicates that drunkenness made prolong the life of patients with $\mathrm{CHF}$ at a time ratio of $(\mathrm{TR}=1.394)$. Therefore patients with CHF drinking little to moderate alcohol were improve the function of heart and the patients can live longer than non drunker with a probability value of 
$(\mathrm{p}=0.010)$. Our study also comparable with other studies [19, 20]. It was shown that that a $59 \%$ lower risk of HF among men who consumed 8 to 14 drinks per week compared with abstainers and only a modest and non-statistically significant association in women. Altogether, there appears to be substantial evidence supporting possible benefits of light-to moderate alcohol consumption on the risk of HF from these observational data. Thus, for patients who do not consume any alcohol, it would be premature to recommend light-tomoderate drinking as a means to lower the risk of $\mathrm{HF}$, given the possible risk of abuse and resulting consequences.

Diabetes Mellitus as a co morbidity were found statistical significant $(p=0.000)$. Diabetes and congestive heart failure (HF) commonly coexist in the same patient, and the presence of diabetes in HF patients is associated with increased adverse events compared to patients without diabetes. Meaning the presence of Diabetes Mellitus as a co morbidity will accelerate the mortality of patients with $\mathrm{CHF}(\mathrm{TR}=0.49)$. This study also confirmed with $[8,21]$. Stroke as a co morbidity were found statistical significant $(\mathrm{p}=0.014)$. The presence of stroke in HF patients is associated with increased adverse events compared to patients without stroke. Meaning the presence of stroke as a co morbidity will accelerate the mortality of patients with $\mathrm{CHF} \quad(\mathrm{TR}=0.799)$. The complication of CHF were increase as the co morbidity increases. This study is confirmed by the previous study [19].

Coronary artery disease as a co morbidity were found statistical significant $(\mathrm{p}=0.012)$. The presence of Coronary artery disease in HF patients is associated with increased adverse events compared to patients without Coronary artery disease. Meaning the presence of Coronary artery disease as a co morbidity will accelerate the mortality of patients with $\mathrm{CHF}(\mathrm{TR}=0.276)$. The complication of CHF were increase as the comorbidity increases. This study also confirmed within a study carried out previously [20, 21]. Therefore physicians should give due attention especially for minimizing the burden of complication of CHF had disease as a co morbidity. $\mathrm{TB}$ is an important clinical variable that affects the lifespan of patients with CHF. Patients with CHF had TB as a co morbidity had a worse survival rate. In other words Patients with CHF had TB as a co morbidity had accelerate the mortality by $(\mathrm{TR}=0.103)$ and it is statistically significant at a $\mathrm{p}$-value of (p-0.000). Our study is also confirmed with the study [20].

\section{Conclusion and Recommendation}

This study is based on a CHF data set derived from a fiveyear retrospective cohort study of patients CHF follow up in the Woldia general and Dessie referral hospital, Northen Ethiopia with an aim of investigating the comparative performance of Cox and parametric models in a survival analysis of time-to death with CHF data. We used AIC and standardized variability of the coefficients for covariates in the models to evaluate the performance among models. In our dataset the proportional hazard assumptions were violated. However, based on AIC the Weibull AFT model indicated an improved fit as compared to the rest parametric counter parts for any combination of variables in the data set. We also found that from different combinations of covariates in the dataset Age, Residence, Nutritional statues, Smoking, Alcoholism, Diabetes mellitus, hypertension, Stroke, Coronary artery disease, Tuberculosis bacillus as a co morbidity and the interaction between age and Tuberculosis bacillus, age and Coronary artery disease, Diabetes mellitus with Hypertension, Hypertension with Nutritional status and age with time yield the smallest possible AIC value for Weibull AFT model suggesting that Weibull model with these predictors is the best to explain the given time to death with $\mathrm{CHF}$ in this dataset compared to the rest parametric models.

Based on the result of the study different factors and parsimonious model are identified for time to mortality data. Researchers in the field of medical sciences are often interested in Cox proportional hazard model more than parametric models. However, it does have the requirement of proportional hazards, which is not always satisfied by the data. If this assumption does not hold, the Cox model can lead to the unreliable conclusions. In these situations, parametric models (such as log logistic, Weibull and Exponential) provide an alternative method to fit survival data even when hazards are not proportional Moreover, under these models we measured the direct effect of the explanatory variables on the survival time and not on a conditional probability, as we do in the Cox regression model. This characteristic allows for an easier interpretation of the results because the parameters measure the effect of the correspondent covariate on the mean lifetime. Parametric models are, therefore, based on a specific distribution for duration times without need to proportional hazard assumptions.

\section{Abbreviations}

AFT: Accelerated Failure Time, CHF: Congestive Heart Failure, DRH: Dessie Referral Hospital, WGH: Woldia General Hospital, HF: Heart Failure, SPSS: Statistical Package for Social Science, STATA: South Texas Art Therapy Association

\section{Competing Interests}

The authors declare that they have no competing interests.

\section{Acknowledgements}

We are grateful to Woldia University for its technical and financial support. We would also like to extend our gratitude to all staff members of WRH and DRH who have directly or indirectly helped us for giving us the data and the successful and smooth completion of this study.

\section{Authors' Contributions}

Habtamu D. conceived the study, participated in data 
collection, performed analysis and interpretation of the data and drafted the paper and prepared all versions of the manuscript. Yenefenta W., Belete A. and Eskeziaw A. assisted in the design, participated in data collection, analysis and revised subsequent drafts of the paper. All authors read and approved the final manuscript.

\section{References}

[1] Agvall. (2014). Heart failure in primar care with specia lemphasis on costs and benefits of a disease management program. Sweden PhD dissertation, Linköping University.

[2] Ponikowski, P. A. (2014). Heart failure: Preventing disease and death worldwide. European Society of Cardiology; from: http://spo.escardio.org/eslides/view.aspx?eevtid $=59 \& \mathrm{f}$, Available.

[3] Owusu, I. B. (2013). Prevalence and etiology of Heart Failure in Patients SeenataTeaching Hospital in Ghana. J Cardiovasc Dis Diagn, 1: 131.

[4] Tantchou, Tchoumi, Jacques, Cabraletal.(2011). Retrieved from The Pan African Medical Journal - ISSN 1937-8688.: http://www.panafrican-med-

journal.com/content/article/8/11/full/.

[5] Cabral, T. S. (2011). Occurrence, etiology and challenges in the management of congestive heart failure in sub-Saharan Africa: experience of the Cardiac Centrein Shisong, Cameroon. Pan African Medical journal, 8: 11.

[6] Misganaw, A. H. -M. -M. (2014). Epidemiology of Major Non-communicable Diseases in Ethiopia. A Systematic Review. $J$ Health Popul Nutr 32 (1), 1-13.

[7] Misganaw, A. H. -M. (2012). The Double Mortality Burden among Adults in Addis Ababa, Ethiopia, 2006-2009. Prev Chronic Dis, 9: 110-142.

[8] Azmera, h. (2015). Survival during Treatment Period of Patients with Severe Heart Failure Admitted to Intensive Care Unit (ICU) at Gondar University Hospital. American journal of health research, 257-269.

[9] Bennett, D. E. (2012). Study protocol: systematic review of the burden of heart failure in low-and middle-income countries. Bennettetat. Systematic reviews, 1: 59.

[10] Cook, C. C. (2013). The annual global economic burden of heart failure. Int $\mathrm{J}$ Cardiol: available from: http: //dx. doi. org/10. 1016/j. ijcard. 2013. 12. 028.
[11] KhalilMurad, M. a. (2012). Frailty and Multiple Comorbidities in the Elderly Patient with Heart Failure: Implications for Management. Heart Fail Rev: doi: 10. 1007/s10741-011-9258-y, 581-588.

[12] Aalen, o. (1989). A linear regression model for the analysis of life times. Statist. Med., 8: 907-925.

[13] Cox, D. (1972). Regression models and life-tables. Journal of the Royal Statistical Society Series B (Methodological), 34 (2): 187-220.

[14] Capell, E. F., Colet, J. C., Miralles, J. D., Saladich, I. J., Wensing, M., Rotellar, J. M. (2013). Survival in Mediterranean Ambulatory Patients With Chronic Heart Failure. A Population-based Study. Rev Esp Cardiol 66 (7): 539-544.

[15] GioloSR, K. J. (2012). Survival Analysis of Patients with Heart Failure: Implications of Time-Varying Regression Effects in Modeling Mortality. PLoS ONE7.

[16] Retrieved from http://Chronic kidney disease and heart failure Bidirectional close link and common the rapeuticgoal Science Direct.html.

[17] BadveSV, RobertsMA, HawleyCM, CassA, GargAX, KrumH, TonkinA, PerkovicV.. (2011). Effects of beta adrenergic antagonists in patients with chronic kidney disease: asystematicreviewandmeta-analysis. J Am Coll Cardiol, 11521161.

[18] Akiomiyoshisha, y. k. (2017). The impact of nutration indices on mortality inpatients with heart failur. Open heart. bmj.(6): e37392. doi: 10. 1371/journal. pone. 0037392.

[19] Clare J Taylor, Ronan Ryan, Linda Nichols, Nicola Gale, FD Richard Hobbs, and Tom Marshall (2017). Survival following a diagnosis of heart failure in primary care. Family Practice, Vol. 34, No. 2, 161-168.

[20] Mulubirhan Tirfe, Teshome Nedi, Desalew Mekonnen and Alemseged Beyene (2020). Treatment outcome and its predictors among patients of acute heart failure at a tertiary care hospital in Ethiopia: a prospective observational study. BMC Cardio vascular Disorders 20: 16.

[21] Saifullah Nasir, M. a (2012). Congestive Heart Failure and Diabetes: Balancing Glycemic Control with Heart Failure Improvement. Winter Center for Heart Failure Research and section of Cardiology; Am J, 110. 